\title{
Enteral resorbable diet versus standard diet in primary sphincter reconstruction: a prospective randomised trial
}

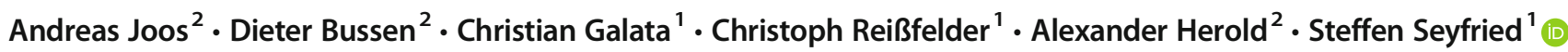

Accepted: 3 February 2021 / Published online: 23 March 2021

(C) The Author(s) 2021

\begin{abstract}
Aim Bowel movements after reconstructive anorectal surgery may negatively affect surgical outcome. This study was aimed to assess any differences between a standard diet (SD) and the enteral resorbable diet (ED) in terms of operative outcomes and patient tolerance after fistulectomy with primary sphincter reconstruction.

Method Adult patients undergoing elective fistulectomy with primary sphincter reconstruction for anorectal and rectovaginal fistulas were eligible for inclusion. Patients were intraoperatively randomised to receive either the ED and peristalsis-inhibiting medication (ED) or a SD. The primary endpoint was the healing rate. Secondary endpoints included continence scores, complications and quality of life. Sample size calculation resulted in the analysis of 60 patients to detect a difference in fistula recurrence of $30 \%$ with $70 \%$ power and a $5 \%$ significance level.

Results Sixty-six patients (24 women) were prospectively and randomly assigned to the $\operatorname{ED}(n=34: 51 \%)$ or a $\operatorname{SD}(n=32 ; 48 \%)$; mean age was 47 (18-74) years. The primary healing rate was 64 out of 66 patients $(96 \%)$. No statistical difference in healing rate was seen between the groups. However, patient satisfaction was significantly higher in the SD group $(P<0.0001)$.

Conclusions Fistulectomy with primary sphincter reconstruction is a safe method with low complication rates. Postoperative stool behaviour has no significant influence on the healing rate but has a significant negative impact on patient satisfaction. Therefore, maintaining a standard diet seems to be preferable following reconstructive anal surgery.

Trial registration The trial was registered with the German Clinical Trials Register (DRKS00020524).
\end{abstract}

Keywords Anal fistula $\cdot$ fistulectomy $\cdot$ Primary reconstruction $\cdot$ Diet $\cdot$ Seton $\cdot$ Recurrence

\section{Introduction}

After reconstructive anorectal surgery, bowel movements can have a negative impact on surgical outcomes. Early postoperative stool passage may lead to mechanical overstretching of the suture and sphincter dehiscence; it also increases the risk of wound infection with resulting impairment of postoperative healing [1,2].

Several different methods of preventing bowel movements are used. The most invasive is a defunctioning enterostomy. Medical bowel confinement, alone or in combination with total

Steffen Seyfried

steffen.seyfried@umm.de

1 Department of Surgery, University Medical Center Mannheim, Medical Faculty Mannheim, Heidelberg University, Theodor-Kutzer-Ufer 1-3, 68167 Mannheim, Germany

2 Deutsches End- und Dickdarm-Zentrum, Mannheim, Germany parenteral nutrition or enteral nutrition using absorbable nutrients, and in combination with peristalsis-inhibiting drugs, is also sometimes applied [3]. The evidence in this field is scarce.

Another trial demonstrated that enteral nutrition is preferable to intravenous nutrition for preventing defecation. The literature has not yet evaluated the question of whether any induced delay of bowel movements in the early postoperative period provides benefits after reconstructive anorectal surgery [3].

This study was aimed to assess any differences between a standard diet (SD) and the enteral resorbable diet with peristaltic inhibiting drugs (ED) in terms of operative outcomes and patient tolerance after fistulectomy with primary sphincter reconstruction.

\section{Method}

Between April 2008 and November 2012, 66 patients were selected for the randomised trial. All subjects underwent 
elective fistulectomy with primary sphincter reconstruction for anorectal and rectovaginal fistulas at the Department of Colorectal Surgery of Mannheim University Hospital, Germany.

Sample size calculations indicated that 60 patients would need to be analysed to detect a difference in fistula recurrence of $30 \%$ with a $70 \%$ power and a $5 \%$ significance level. Sixtysix patients were initially chosen to allow for dropouts during follow-up.

\section{Patients}

All consecutive patients were operated on by three colorectal surgeons. Exclusion criteria were inflammatory bowel disease, recurrent fistula, previous radiation or chemotherapy, infectious diseases (e.g. HIV) or steroid therapy as well as enterostomy. The preoperative diagnosis was confirmed by an independent specialised coloproctologist through clinical examination, proctoscopy, rectoscopy and endorectal ultrasound. Fistulas were classified as either distal fistulas, where the tract crosses the distal third of the sphincter; intermediate fistulas, where the tract crosses the middle third of the sphincter; and proximal fistulas, where the tract crosses the proximal third of the sphincter.

All patients answered questions in the two questionnaires listed below and were placed along analogue scales for pain (1 $=$ no pain $; 10=$ maximum pain) and general well-being/satisfaction $(1=$ very satisfied; $6=$ very unsatisfied $)$.

\section{Questionnaires}

Anorectal function was assessed using two different scores:

(1) The Cleveland Clinic Incontinence Score (CCS) compares incontinence 3 months after surgery to baseline. Possible CCS scores range from 0 (continent) to 20 (totally incontinent).

(2) The Rockwood Score (Faecal Incontinence Quality of Life-FIQL) evaluates different quality-of-life aspects ('lifestyle', 10 items; 'coping/behaviour', 9 items; 'depression/self-perception', 7 items; and 'embarrassment', 3 items) on a scale of 1 to 5 , with 1 indicating a lower functional QoL. Patients answered the questionnaire before the operation and at three follow-up intervals (1 week, 3 months and 12 months after surgery). If direct personal contact was not possible, the survey was carried out in the form of a telephone interview.

\section{Randomisation}

Patients were randomised prospectively by opening an envelope immediately after surgery to one of two study groups, with the surgeon and the physician responsible for follow-up visits blinded to postoperative nutritional regime. The mode of surgery was not influenced by this study.

Both groups received the same preoperative bowel lavage solution (3 1 DelcoprepTM, DeltaSelect GmbH, Dreieich, Germany) and a single dose of cefazolin ( $2 \mathrm{~g}$ i.v.) or ciprofloxacin (200 $\mathrm{mg}$ i.v.) in patients with penicillin allergies, and metronidazole (500 mg i.v.) immediately before surgery. On the day of surgery, patients received $1000-2000 \mathrm{ml}$ of isotonic crystalloid solution intravenously and $500 \mathrm{ml}$ of tea or water. From the first postoperative day, both groups were allowed to drink clear liquids.

\section{Control group}

Patients in the SD group were allowed to drink clear liquids the day of surgery and eat normal meals the day after surgery. No restrictions on eating and drinking were imposed on those patients thereafter.

\section{Intervention group}

From the first postoperative day onwards, the RD group was offered five cups of Clinutren fruitTM (Nestlé Nutrition comp., Frankfurt, Germany) and two cups of OPD PeptamenTM (Nestlé Nutrition comp., Frankfurt, Germany). This quantity was the maximum allowed per day. In addition, patients received $2 \mathrm{mg}$ loperamide once a day from the day of surgery until the 6th day after surgery. Beginning on the 7th day following surgery, this group was permitted to eat a normal diet, and no more loperamide was administered.

From the day of surgery until the 6th postoperative day, the amount of food consumed daily and the time of first defecation was documented. Pain during the first defecation was recorded on a visual analogue scale from 1 to $10(1=$ no pain; $10=$ maximum pain). Patient satisfaction with the type of nutrition offered was evaluated by an analogue scale of 1 (very satisfied) to 6 (dissatisfied). Additionally, duration of hospital stay and length of time unable to work were documented. Follow-up examinations were performed after 2-4 weeks, after 6-12 weeks and every 6 months thereafter to determine or rule out fistula recurrence. The physician was not aware of whether the patient had received normal food or special enteral nutrition. In both groups, visual evaluation, digital rectal examination and proctoscopy were performed in order to detect fistula recurrence. During these follow-up examinations, continence was evaluated by Rockwood scores and CCS, and return to work was documented. The surgical technique was standardised as described before [4].

The trial was registered with the German Clinical Trials Register (DRKS00020524).

The study was approved by the local ethics committee (2017-819R-MA). 
All patients gave their informed consent to participate.

\section{Endpoints and study visits}

The main indicator used in this trial was the healing rate. This was defined as the complete healing of all tracts and external and internal openings, as well as no further secretions detected in clinical examination. All patients were evaluated after 2-4 weeks, 4-6 weeks, 6-12 weeks and every 6 months after the operation date, if possible. Wound healing after 12 weeks and beyond was defined as prolonged wound healing. Dehiscence of the adapted sphincter muscle could be easily detected 2-4 weeks after operation via inspection and palpation, as the external wound is still open at this point. The latter examination is mandatory and is performed by the operating surgeon, who is aware of the patient's intraoperative status and the postoperative situation.

Failure to heal resulted in persisting fistulas. Primary healing with subsequent recurrence was also observed. Both outcomes were included in the term 'recurrence' in this trial.

Secondary endpoints were pain during the first defecation following surgery, satisfaction with the type of nutrition offered, duration of hospitalisation and length of inability to work measured as described above. The difference of the Rockwood score at 4 timepoints, CCS score before surgery and 3 months afterwards were also recorded.

\section{Statistical analysis}

To compare the outcomes of the two groups, the following tests were applied where appropriate: Chi2 test, Fisher's exact test, Cochran-Armitage trend test, two-sample t-test and Mann-Whitney U-test. A logistic regression analysis was not suitable due to low event rates ('recurrence'). A test result with a $P$-value less than 0.05 is considered significant. All statistical calculations were conducted with SAS, release 9.3 (SAS Institute Inc., Cary, NC, USA).

\section{Results}

The 66 patients in the study included 42 men and 24 women. Demographic data, as well as coloproctological history and distribution of both groups, are shown in Table 1. Primary healing rate, without any complications, after follow-up of a median 28 months (ED $26 /$ SD 30 month) was $89.4 \%$ (59 out of 66 ), or $88.2 \%$ for the ED group and $90.6 \%$ for the SD group. One patient in each group had a partial dehiscence. Both individuals were treated conservatively and did not require further operation. One patient in the RD group showed prolonged wound healing, as did 2 patients in the SD group.
Both recurrences occurred in the $\mathrm{RD}$ group, but this difference was not significant $(P=0.163)$. After 1 year, all complications healed conservatively, resulting in a long-term healing rate of $94.1 \%$ in the RD group and $100 \%$ in the SD group. These differences were not statistically significant (Table 2).

Participants in the SD group had a significantly earlier first postoperative defecation $(P=0.006)$. Length of hospital stay did not differ between the groups $(P=0.112)$. Most patients were discharged after 4-5 days. Overall satisfaction was significantly higher in the SD group compared with the RD group $(P<0.001)$.

There was no statistically significant difference between the $\mathrm{SD}$ and $\mathrm{RD}$ groups for pain during first defecation $(P=$ 0.294) (Table 2). Time until return to work was not significantly different.

The present study revealed a stable timeline in both continence scores. Values of both scores did not differ between groups (Rockwood $P=0.23 / \mathrm{CCS} P=0.62$ ). The course of the validated Rockwood Scores (based on the means of both groups) at the respective questionnaire time is shown in Fig. 1.

Overall, four patients (two in each group, all women) had a ventral fistula, but none had contact with the vagina.

All patients included in this study were able to complete the follow-up visits until 12 months after the operation. In some cases, the follow-ups were conducted by telephone interview at 3 and 12 months.

\section{Discussion}

This work is the only prospectively randomised trial that examines the influence of postoperative nutrition on the outcome of fistulectomy with primary sphincter reconstruction.

Its main finding is that a special postoperative diet to avoid early defecation after fistulectomy with sphincter reconstruction does not improve postoperative outcomes and is therefore unnecessary. Furthermore, such a diet causes more discomfort for the patient (Fig. 2). The safety, feasibility, and excellent results of fistulectomy with primary sphincter reconstruction were again confirmed [4-8]. This trial and its results fill a gap in the existing research. Given its use of long-term follow-ups, this study's findings on operative outcomes should also be considered valid. These results are in accordance with other (non-randomised) trials that examined the effect of nutritional regimes on the outcome of coloproctological interventions $[3,9,10]$. A retrospective British study, focused on postoperative management after sphincter reconstruction[9], divided patients into three groups: pharmacological stool prevention, protective ileostomy and normal diet with laxatives. No significant differences were found in rates of infection, wound dehiscence or surgical outcome. Constipation was more common in the pharmacological stool prevention group. An 
Table 1 Preoperative data

\begin{tabular}{|c|c|c|c|c|c|c|}
\hline & & $\mathrm{RD}^{*}$ & $\%$ per group & $\mathrm{SD}^{* *}$ & $\%$ per group & $p$ \\
\hline$n$ & & 34 & 51.5 & 32 & 48.5 & 0.61 \\
\hline Sex & $\begin{array}{l}\mathrm{m} \\
\mathrm{w}\end{array}$ & $\begin{array}{l}19 \\
15\end{array}$ & $\begin{array}{l}55.9 \\
44.1\end{array}$ & $\begin{array}{l}23 \\
9\end{array}$ & $\begin{array}{l}71.9 \\
28.1\end{array}$ & 0.08 \\
\hline Age & & $46(18-71)$ & & $48(23-74)$ & & 0.39 \\
\hline Smoker & $\begin{array}{l}\text { Current } \\
\text { Until } 12 \text { months preoperative }\end{array}$ & $\begin{array}{l}7 \\
3\end{array}$ & $\begin{array}{l}20.6 \\
8.8\end{array}$ & $\begin{array}{l}7 \\
4\end{array}$ & $\begin{array}{l}21.9 \\
12.5\end{array}$ & 0.62 \\
\hline Previous proctological surgery & $\begin{array}{l}\text { Any surgery } \\
\text { Fistula surgery }\end{array}$ & $\begin{array}{l}34 \\
2\end{array}$ & $\begin{array}{l}51.5 \\
5.9\end{array}$ & $\begin{array}{l}32 \\
6\end{array}$ & $\begin{array}{l}48.5 \\
18.8\end{array}$ & $\begin{array}{l}0.37 \\
0.08\end{array}$ \\
\hline Type of fistula & $\begin{array}{l}\text { Distal } \\
\text { Intermediate } \\
\text { High }\end{array}$ & $\begin{array}{l}1 \\
29 \\
4\end{array}$ & $\begin{array}{l}2.9 \\
85.3 \\
11.8\end{array}$ & $\begin{array}{l}0 \\
31 \\
1\end{array}$ & $\begin{array}{l}0 \\
96.9 \\
3.1\end{array}$ & 0.56 \\
\hline Length of sphincter & $\begin{array}{l}<3 \mathrm{~cm} \\
3-4 \mathrm{~cm} \\
4-6 \mathrm{~cm}\end{array}$ & $\begin{array}{l}11 \\
13 \\
10\end{array}$ & $\begin{array}{l}32.4 \\
38.2 \\
29.4\end{array}$ & $\begin{array}{l}8 \\
17 \\
7\end{array}$ & $\begin{array}{l}25 \\
53.1 \\
21.9\end{array}$ & 0.84 \\
\hline Scores preoperative & $\begin{array}{l}\text { CCS median (range) } \\
\text { Rockwood }\end{array}$ & $\begin{array}{l}2.3(0-8) \\
3.8(1.9-4)\end{array}$ & & $\begin{array}{l}1.6(0-12) \\
3.9(2.1-4)\end{array}$ & & $\begin{array}{l}0.52 \\
0.47\end{array}$ \\
\hline
\end{tabular}

*ED $=$ enteral resorbable diet

$* * \mathrm{SD}=$ standard diet

increased morbidity was observed in the protective ileostomy group.
Based on published data and this randomised trial, a special diet in the context of coloproctological surgery is discouraged.

Table 2 Operative outcomes

\begin{tabular}{|c|c|c|c|c|c|c|}
\hline & & $\mathrm{ED}^{*}$ & $\%$ (per group) & $\mathrm{SD}^{* *}$ & $\%$ (per group) & $p$ \\
\hline$n$ & & 34 & 50.1 & 32 & 49.23 & n.s. \\
\hline \multirow[t]{9}{*}{ Pain during first defecation } & 1 & 14 & 41.2 & 14 & 43.7 & n.s. \\
\hline & 2 & 6 & 17.7 & 12 & 37.5 & \\
\hline & 3 & 7 & 20.6 & 5 & 15.6 & \\
\hline & 4 & 5 & 14.7 & 1 & 3.2 & \\
\hline & 5 & & & & & \\
\hline & 6 & 1 & 2.9 & & & \\
\hline & 7 & & & & & \\
\hline & 8 & 1 & 2.9 & & & \\
\hline & 9 & & & & & \\
\hline Recurrence & & 2 & 5.9 & 0 & 0 & n.s. \\
\hline \multirow[t]{2}{*}{ Complications } & Prolonged wound healing & 1 & & 2 & & n.s. \\
\hline & Partial dehiscence & 1 & & 1 & & \\
\hline \multirow[t]{5}{*}{ Hospital stay (days) } & 3 & 1 & 2.9 & 1 & 3.1 & n.s. \\
\hline & 4 & 10 & 29.4 & 4 & 12.5 & \\
\hline & 5 & 16 & 47 & 25 & 78.1 & \\
\hline & 6 & 6 & 17.7 & 2 & 6.3 & \\
\hline & 7 & 1 & 2.9 & 0 & & \\
\hline \multirow[t]{7}{*}{ First defecation } & Day 1 & 10 & 29.4 & 19 & 59.4 & $* 0.006$ \\
\hline & Day 2 & 4 & 11.8 & 8 & 25 & \\
\hline & Day 3 & 1 & 2.9 & 2 & 6.3 & \\
\hline & Day 4 & & & & & \\
\hline & Day 5 & 2 & 5.9 & & & \\
\hline & Day 6 & 1 & 2.9 & & & \\
\hline & Not before discharge & 16 & 47.1 & 3 & 9.4 & \\
\hline Days off work (days) & Mean (standard deviation) & $21.4(11.9)$ & & $26.4(12.4)$ & & n.s. \\
\hline CCS 3 month postoperative & CCS median (range) & $3.2(0-12)$ & & $2.5(0-12)$ & & n.s. \\
\hline
\end{tabular}

*ED $=$ enteral resorbable diet

**SD $=$ standard diet 


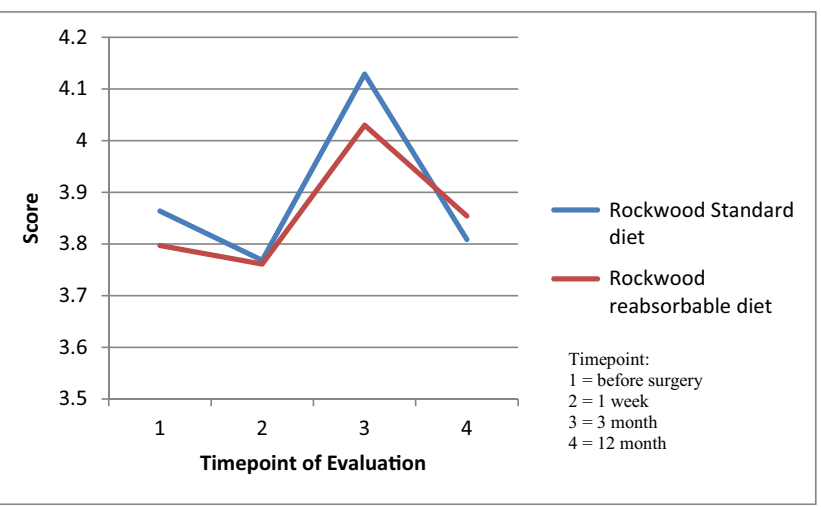

Fig. 1 Rockwood score

As early defecation does not influence surgical outcomes regarding sphincter reconstruction, perioperative enteral and early nutrition is advantageous. Early defecation could be avoided by a resorbable diet and inhibiting medication (loperamide). Our group has already shown that this method is feasible for avoiding defecation [3].

As the results of fistulectomy with primary sphincter reconstruction show very low complication rates and recurrences, and since the majority of these patients were operated on without oral bowel preparation, the effects of oral bowel preparation with antibiotics might be assessed as rather minimal [4]. However, studies evaluating the influence of bowel preparation specifically are lacking and might provide more conclusive evidence. On the basis of the available data, particularly recent data on oral antibiotic bowel preparation[11], no conclusive statement can be made regarding the effects of bowel preparation on operative results in coloproctology.

Since the CCS was only measured at two timepoints (preoperatively and 3 months after surgery), no graphical representation is provided. At the time this study was planned, there were no published data on fistulectomies with primary sphincter reconstruction. As later evaluations showed $[4,5,8,12$, 13], the success rate of this method had been underestimated. In our calculations, we assumed a recurrence rate of $50 \%$ in the normal food group of $50 \%$ and $20 \%$ in the resorbable group. In retrospect, the recurrence rate was clearly

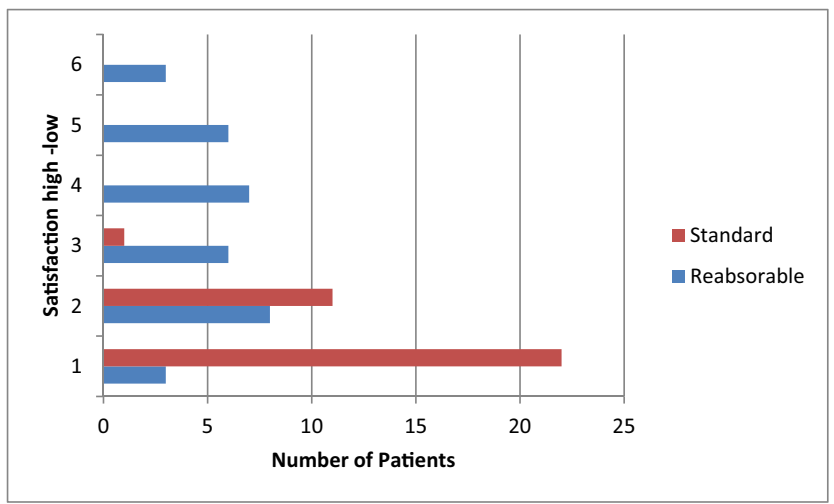

Fig. 2 Patients satisfaction overestimated, and this must be discussed as a weakness of the study.

Regardless of nutritional regime, the results show that fistulectomy with primary sphincter reconstruction is a safe therapy, since the values did not change significantly in comparing preoperative to postoperative patients. As the literature shows, continence problems after sphincter reconstructions are a rare complication.

In the only randomised study comparing fistulotomy and sphincter reconstruction with advancement flaps and postoperative incontinence[9], the results of the Wexner score $(0.64$ versus 0.48 ) were comparable. Perez et al. [14] showed that continence was improved after this reconstructive operation in patients with preoperative continence disorders, without compromising fully continent patients $[4,8,15]$.

\section{Summary}

Early postoperative defecation has no negative impact on surgical results, and certainly no impact on continence. Since the well-being of the patient is already impaired, a special diet might best be avoided. Fistulectomy with primary sphincter reconstruction is a feasible procedure resulting in a low recurrence rate that does not compromise continence. A question remains as to whether preoperative oral intestinal irrigation (especially with selective intestinal decontamination by antibiotics) is an advantage, and this should be investigated further.

Supplementary Information The online version contains supplementary material available at https://doi.org/10.1007/s00384-021-03878-x.

Authors' contributions All authors contributed to the study conception and design. Material preparation, data collection and analysis were performed by AJ and SS. The first draft of the manuscript was written by SS and all authors commented on previous versions of the manuscript. All authors read and approved the final manuscript.

Funding Open Access funding enabled and organized by Projekt DEAL.

Data availability The datasets generated during and/or analysed during the current study are available from the corresponding author on reasonable request.

\section{Declarations}

Ethics approval The study was approved by the local ethics committee (2017-819R-MA).

Consent to participate Informed consent was obtained from all individual participants included in the study.

Consent for publication Patients signed informed consent regarding publishing their data and photographs 
Conflicts of interest The authors declare that they have no conflict of interest.

Open Access This article is licensed under a Creative Commons Attribution 4.0 International License, which permits use, sharing, adaptation, distribution and reproduction in any medium or format, as long as you give appropriate credit to the original author(s) and the source, provide a link to the Creative Commons licence, and indicate if changes were made. The images or other third party material in this article are included in the article's Creative Commons licence, unless indicated otherwise in a credit line to the material. If material is not included in the article's Creative Commons licence and your intended use is not permitted by statutory regulation or exceeds the permitted use, you will need to obtain permission directly from the copyright holder. To view a copy of this licence, visit http://creativecommons.org/licenses/by/4.0/.

\section{References}

1. Asbury WH, Hooks VH, DiPiro JT, Bowden TA (1987) Use of oral opiates and diet modification as an alternative to surgical colostomy after complex anorectal procedures. Clin Pharm 6:649-651

2. Gordon PH (1976) The chemically defined diet and anorectal procedures. Can J Surg 19:511-513

3. Joos AK, Palma P, Jonescheit JO, Hasenberg T, Herold A (2008) Enteral vs parenteral nutrition in reconstructive anal surgery - a prospective-randomized trial. Color Dis 10:605-609. https://doi. org/10.1111/j.1463-1318.2007.01403.x

4. Seyfried S, Bussen D, Joos A, Galata C, Weiss C, Herold A (2018) Fistulectomy with primary sphincter reconstruction. Int J Color Dis 33:911-918. https://doi.org/10.1007/s00384-018-3042-6

5. Roig JV, García-Armengol J, Jordán JC, Moro D, García-Granero E, Alós R (2010) Fistulectomy and sphincteric reconstruction for complex cryptoglandular fistulas. Color Dis 12:e145-e152. https:// doi.org/10.1111/j.1463-1318.2009.02002.x

6. Ratto C, Litta F, Parello A, Zaccone G, Donisi L, de Simone V (2013) Fistulotomy with end-to-end primary sphincteroplasty for anal fistula. Dis Colon Rectum 56:226-233. https://doi.org/10. 1097/DCR.0b013e31827aab72
7. Hirschburger M, Schwandner T, Hecker A, Kierer W, Weinel R, Padberg W (2014) Fistulectomy with primary sphincter reconstruction in the treatment of high transsphincteric anal fistulas. Int $\mathrm{J}$ Color Dis 29:247-252. https://doi.org/10.1007/s00384-013-1788-4

8. Arroyo A, Pérez-Legaz J, Moya P, Armañanzas L, Lacueva J, Pérez-Vicente F, Candela F, Calpena R (2012) Fistulotomy and sphincter reconstruction in the treatment of complex fistula-inano. Ann Surg 255:935-939. https://doi.org/10.1097/SLA. 0b013e31824e9112

9. Ingham C, Rihani H, Surg RN-BJ (1997) undefined Perioperative management of patients undergoing anal sphincter repair

10. Mahony R, Behan M, O'Herlihy C, O'Connell PR (2004) Randomized, clinical trial of bowel confinement vs. laxative use after primary repair of a third-degree obstetric anal sphincter tear. Dis Colon Rectum 47:12-17. https://doi.org/10.1007/s10350-0030009-6

11. Nelson RL BM (2014) Cochrane database of systematic reviews antimicrobial prophylaxis for colorectal surgery (Review). https:// doi.org/10.1002/14651858.CD001181.pub4

12. Roig G-A, Jordán et al (1999) Immediate reconstruction of the anal sphincter after fistulectomy in the management of complex anal fistulas. Color Dis 1:137-140. https://doi.org/10.1046/j.14631318.1999.00021.x

13. Kotze PG, Shen B, Lightner A, Yamamoto T, Spinelli A, Ghosh S, Panaccione R (2018) Modern management of perianal fistulas in Crohn's disease: future directions. Gut 67:1181-1194. https://doi. org/10.1136/gutjnl-2017-314918

14. Perez F, Arroyo A, Serrano P, Sánchez A, Candela F, Perez MT, Calpena R (2006) Randomized clinical and manometric study of advancement flap versus fistulotomy with sphincter reconstruction in the management of complex fistula-in-ano. Am J Surg 192:34 40. https://doi.org/10.1016/j.amjsurg.2006.01.028

15. Wexner SD, Marchetti F, Jagelman DG (1991) The role of sphincteroplasty for fecal incontinence reevaluated: a prospective physiologic and functional review. Dis Colon Rectum 34:22-30

Publisher's note Springer Nature remains neutral with regard to jurisdictional claims in published maps and institutional affiliations. 